\title{
Audiodescrição como ferramenta do Desenho Universal para a Aprendizagem: inclusão de crianças com deficiência visual na Educação Infantil
}

\author{
Audio description as a tool of Universal Design for Learning: inclusion of \\ visually impaired children in early childhood education \\ La Audiodescripción como herramienta de Diseño Universal para el \\ Aprendizaje: inclusión de niños con discapacidad visual en la educación \\ infantil
}

Aguijane Lopes Menezes

Graduada pelo Instituto Federal de Brasília, Brasília, DF, Brasil

E-mail: aguijanelopesmenezes@gmail.com ORCID: https://orcid.org/0000-0003-0934-1859

Cândida Beatriz Alves

Professora doutora do Instituto Federal de Brasília, Brasília, DF, Brasil

E-mail: candida.alves@gmail.com ORCID: https://orcid.org/0000-0002-7318-5398

Recebido em 05 de junho de 2021

Aprovado em 04 de outubro de 2021

Publicado em 29 de outubro de 2021

\section{RESUMO}

Este trabalho visa contribuir para o processo de inclusão de crianças com deficiência visual na Educação Infantil, a partir da perspectiva histórico-cultural. A audiodescrição (AD) é uma tecnologia assistiva, que foi criada para tornar cinema e teatro acessíveis às pessoas cegas. Com o passar das décadas, a sua utilização em espaços educativos tem se mostrado de fundamental importância no processo de inclusão escolar de pessoas com deficiência visual. $O$ objetivo deste trabalho, é apresentar a $A D$ como uma ferramenta do Desenho Universal para a Aprendizagem (DUA) que, ao promover a inclusão de crianças com deficiência visual na Educação Infantil, traz benefícios ao desenvolvimento de toda a turma. Metodologicamente, passamos inicialmente pelo levantamento de Políticas Públicas de Inclusão de alunos com deficiência, que dialogam com o DUA e buscam construir um ambiente propício para a aprendizagem do maior número possível de alunos. Em seguida, apresentam-se estudos sobre o processo de inclusão, especificamente da criança com deficiência visual, e demonstra-se como a $A D$ pode ser decisiva para que o aluno que não enxerga tenha mais, e melhores, oportunidades de aprender. Diante dos estudos, concluise que o docente que adota estratégias bem delineadas, com foco na inclusão de crianças com deficiência visual na Educação Infantil, contribui para o aprendizado e desenvolvimento de todos.

Palavras-chave: Inclusão Escolar; Desenho Universal para a Aprendizagem; Audiodescrição. 
http://dx.doi.org/10.5902/1984686X66118

\section{ABSTRACT}

This work aims to contribute to the process of inclusion of visually impaired children in Early Childhood Education, from the historical-cultural perspective. Audio description (AD) is an assistive technology, created to make cinema and theater accessible to blind people. Over the decades, its use in educational spaces has proved to be of fundamental importance in the process of school inclusion of people with visual impairments. The objective of this work is to present AD as a tool of Universal Design for Learning (UDL) that, by promoting the inclusion of visually impaired children in Early Childhood Education, brings benefits to the development of all. Methodologically, we initially went through Public Policies for inclusion of students with disabilities, who dialogue with UDL and seek to build an environment conducive to the learning of as many students as possible. Then, studies are presented on the inclusion process, specifically of the visually impaired child, and demonstrate how the AD can be decisive so that the child who does not see has more and better opportunities to learn. In view of the studies, it is concluded that the teacher who adopts well-designed strategies, focusing on the inclusion of children with visual impairments in Early Childhood Education, contributes to the learning and development of all.

Keywords: School Inclusion; Universal Design for Learning; Audio description.

\section{RESUMEN}

Este trabajo intenta contribuir al proceso de inclusión del niño con discapacidad visual en la Educación Infantil, desde la perspectiva histórico-cultural. La Audiodescripción (AD) es una tecnología de asistencia, que se creó para hacer que el cine y el teatro sean accesibles para las personas ciegas. A lo largo de las décadas, su uso en los espacios educativos ha demostrado ser de fundamental importancia en el proceso de inclusión escolar de las personas con discapacidad visual. El objetivo de este trabajo es presentar la $A D$ como una herramienta de Diseño Universal para el Aprendizaje (DUA) que, al promover la inclusión de niños con discapacidad visual en la Educación Infantil, trae beneficios para el desarrollo de todos los niños. Metodológicamente, inicialmente pasamos por Políticas Públicas para la Inclusión de estudiantes con discapacidad, que dialogan con el Diseño Universal para el Aprendizaje, y buscan construir un ambiente propicio para el aprendizaje de la mayor cantidad de estudiantes posible. Luego, se presentan estudios sobre el proceso de inclusión, específicamente del niño con discapacidad visual, y se demuestra cómo el AD puede ser determinante para que el alumno que no ve tenga más y mejores oportunidades de aprender. A la vista de los estudios, se concluye que el docente que adopta estrategias bien diseñadas, con un enfoque en la inclusión de niños con discapacidad visual en la Educación Infantil, contribuye al aprendizaje y desarrollo de toda la clase.

Palabras clave: Inclusión Escolar; Diseño universal para el aprendizaje; Audiodescripción. 
http://dx.doi.org/10.5902/1984686X66118

\section{Introdução}

De acordo com dados do último censo demográfico do IBGE, existem, no Brasil, cerca de 35,7 milhões de pessoas com algum nível de deficiência visual, o que representa 18,8\% da população brasileira. Dentre as pessoas que declararam ter alguma deficiência, a visual é a mais recorrente em todas as faixas etárias e em todos os estados brasileiros (IBGE, 2010). Considerando que a Educação Infantil é a etapa inicial no processo de educação formal dos indivíduos, o processo de inclusão realizado nesse período pode ser decisivo no desenvolvimento integral da criança com deficiência visual. Para que alunos cegos, ou com baixa visão, possam participar de forma equitativa com os demais das atividades propostas no ambiente educacional, sem prejuízo no seu processo de aprendizagem, é indispensável que o profissional docente tenha estratégias bem definidas.

Por consistir na transformação de todo conteúdo visual em verbal, a Audiodescrição (AD) contorna barreiras, podendo ser compreendida como uma tecnologia assistiva que torna possível, para pessoas cegas, o acesso à informação contida em imagens (fotografias, ilustrações, slides, mapas, expressões corporais etc.) em equidade de condições com os videntes. O uso educacional da AD tem sido cada vez mais reconhecido e divulgado (MOTTA, 2016; SILVA, 2015; VERGARA-NUNES, 2016), porém, apesar de já ter sua importância consolidada em alguns segmentos educacionais, como a educação a distância (BRAGA; ARAÚJO, 2015; RIOS et al, 2016), ainda há poucos estudos a respeito da AD nos diferentes níveis da educação básica, sobretudo na Educação Infantil (AZEVEDO et al, 2019; COZENDEY; COSTA, 2018; PASSERINO; CRUZ, 2017; PAVÃO; PAVÃO, 2020).

Nesse contexto, esse estudo teórico centrou-se na $A D$ como uma ferramenta que, alinhada com os princípios do Desenho Universal para a Aprendizagem (DUA), tem o potencial de facilitar processos de ensino-aprendizagem e promover o desenvolvimento tanto das crianças com deficiência visual, quanto das demais na Educação Infantil. O DUA é um modelo prático, que utiliza abordagens flexíveis a fim de ampliar oportunidades de aprendizagem para o maior número possível de estudantes, com ou sem deficiências (BOCK; GESSER; NUERNBERG, 2018; ZERBATO; MENDES, 2018). Assim, a pergunta que guiou essa pesquisa foi: como a AD pode, ao contribuir para a inclusão de crianças com deficiência visual na Educação Infantil, trazer benefícios para toda a turma?

Considerando que a Educação Infantil é uma etapa em que os educandos ainda não foram alfabetizados, e que os recursos imagéticos são amplamente utilizados como 
http://dx.doi.org/10.5902/1984686X66118

materiais de apoio à aprendizagem, entendemos que é de extrema importância que o profissional docente busque alternativas e adaptações aos materiais utilizados em sala de aula, para que todos tenham a oportunidade de acessar as informações compartilhadas (MOTTA, 2016). A partir da busca por estudos que amparassem e relacionassem os conceitos de acessibilidade, tecnologia assistiva, Educação Infantil, inclusão e Desenho Universal para a Aprendizagem, e tomando como base a teoria histórico-cultural de Lev Vigotski, estabeleceu-se, nessa pesquisa, o objetivo geral de apresentar a AD como uma ferramenta do Desenho Universal para a Aprendizagem (DUA) que, ao promover a inclusão de crianças com deficiência visual na Educação Infantil, traz benefícios ao desenvolvimento de toda a turma.

À luz desse objetivo, esse texto está assim dividido: o primeiro tópico traz discussões sobre políticas educacionais de inclusão; o segundo trata da importância do DUA; no terceiro tópico, é apresentada a AD como ferramenta pedagógica de inclusão; no quarto, apresentamos a Educação Infantil e seus direitos de aprendizagem legalmente garantidos, debatemos o desenvolvimento a partir da perspectiva histórico-cultural e trazemos a AD como ferramenta de inclusão de crianças com deficiência visual. Por fim, concluímos 0 trabalho retomando o percurso realizado e reforçando as possibilidades que se abrem a partir do uso pedagógico da AD.

\section{Políticas Educacionais de Inclusão}

Inclusão é o processo pelo qual os sistemas sociais comuns são tornados adequados para toda a diversidade humana (MANTOAN, 2015; SASSAKI, 2009). De acordo com Bruno (2006, p. 14), "a inclusão é um processo complexo que configura diferentes dimensões: ideológica, sociocultural, política e econômica”. A compreensão de que a inclusão demanda, de maneira primordial, uma educação voltada para a coletividade, sem perder de vista as singularidades, tomou forma a partir de importantes convenções e documentos ao longo do século XX.

Com a Declaração Mundial sobre Educação para Todos (UNESCO, 1990) e a Declaração de Salamanca (UNESCO, 1994), os alunos com deficiência foram amparados e tiveram seus direitos a uma educação de qualidade reforçados. A partir desses documentos, enfatizou-se que as pessoas com necessidades educativas especiais precisariam ter acesso garantido às escolas comuns, que deveriam incluí-las com base em uma pedagogia centrada na criança, observando suas necessidades. 
http://dx.doi.org/10.5902/1984686X66118

Em consonância com tais formulações, a Lei de Diretrizes e Bases da Educação Nacional (LDB), Lei no 9.394/96, no artigo 59, preconiza que os sistemas de ensino devem assegurar aos educandos com deficiência, transtornos globais do desenvolvimento e altas habilidades, ou superdotação, métodos e recursos educativos para atender suas necessidades, "bem como professores do ensino regular capacitados para a integração desses educandos nas classes comuns" (BRASIL, 1996).

Em 2001, o Plano Nacional da Educação (PNE) inaugurava a chamada década da educação, afirmando que os esforços daquele período deveriam se voltar para a inclusão, de modo que todas as escolas contemplassem a diversidade humana. Naquele momento, chamou-se a atenção para a ineficiente formação dos profissionais da educação e para os problemas na acessibilidade e no atendimento educacional especializado como fatores que não permitiam a efetivação do sistema educacional inclusivo (BRASIL, 2001).

Com isso, novos documentos seguiram reforçando a importância da inclusão, detalhando-a e ampliando seu escopo, com destaque para a Política Nacional de Educação Especial na Perspectiva da Educação Inclusiva (PNEE-PEI), de 2008, que assegurou o suporte da Educação Especial ao seu público-alvo desde a Educação Infantil até o Ensino Superior (BRASIL, 2008). No entanto, as ações previstas nos diversos níveis ainda carecem de investimentos em operacionalização para adoção de medidas práticas coerentes com a perspectiva inclusiva.

Com o objetivo de assegurar que o processo de inclusão fosse adequado para os alunos com deficiência, em 2014, o novo PNE estabeleceu uma meta específica para a Educação Especial: a de garantir um sistema educacional inclusivo para os alunos com deficiência, transtornos globais do desenvolvimento e altas habilidades ou superdotação. Reforçou-se que todas as escolas são responsáveis por realizar os ajustes necessários ao seu aprendizado, oferecendo materiais didáticos acessíveis e recursos de Tecnologia Assistiva (TA) (BRASIL, 2014).

A partir das legislações e políticas apresentadas, observa-se o foco em garantir que a educação de qualidade contemple a todos, ou seja, que se traduza em propostas pedagógicas fundamentalmente inclusivas, que abranjam, de fato, a diversidade humana. Assim, ao discutirmos as especificidades de cada deficiência, e as atividades e práticas mais adequadas para cada sujeito singular, deve-se concomitantemente ressaltar aquelas propostas que possam estimular a todos, repensando processos de ensino-aprendizagem e promovendo o desenvolvimento de estudantes com diferentes especificidades 
http://dx.doi.org/10.5902/1984686X66118

(PLETSCH; SOUZA; ORLEANS, 2017). É o que pretendemos aprofundar a seguir sob a ótica do Desenho Universal para a Aprendizagem (DUA).

\section{Desenho Universal para a Aprendizagem: potencialidades de desenvolvimento}

A Convenção Internacional sobre os Direitos das Pessoas com Deficiência (2007), promulgada no Brasil em 2009, destaca que "não é o limite individual que determina a deficiência, mas sim as barreiras existentes nos espaços, no meio físico, no transporte, na informação, na comunicação e nos serviços" (BRASIL, 2009). Segundo a Lei Brasileira de Inclusão da Pessoa com Deficiência (LBI), Lei no 13.146, barreiras podem ser definidas como

qualquer entrave, obstáculo, atitude ou comportamento que limite ou impeça a participação social da pessoa, bem como o gozo, a fruição e o exercício de seus direitos à acessibilidade, à liberdade de movimento e de expressão, à comunicação, ao acesso à informação, à compreensão, à circulação com segurança, entre outros (BRASIL, 2015).

Nesse contexto, ao dispor sobre o conceito de acessibilidade, a LBI afirma que essa se refere à possibilidade e à condição de "utilização, com segurança e autonomia, de espaços, mobiliários, equipamentos urbanos, edificações, transportes, informação e comunicação (...) por pessoa com deficiência ou com mobilidade reduzida" (BRASIL, 2015). Compreende-se, dessa forma, que a acessibilidade não se limita apenas aos aspectos arquitetônicos, como construção de rampas ou pisos táteis.

A acessibilidade tem sido associada, desde os anos 1970, com a ideia de Desenho Universal, segundo o qual os ambientes devem estar aptos a serem usados por qualquer pessoa, independentemente de características físicas, sensoriais ou intelectuais (VERGARA-NUNES; MACHADO; VANZIN, 2011; RICARDO; SAÇO; FERREIRA, 2017). De acordo com a LBI, Desenho Universal é definido como a "concepção de produtos, ambientes, programas e serviços a serem usados por todas as pessoas" (BRASIL, 2015). Desse modo, projetar a inclusão sob os princípios do Desenho Universal beneficia a todos, tenham ou não qualquer tipo de deficiência.

Em resposta ao desafio de garantir a inclusão nas escolas de ensino regular e promover a aprendizagem de todos, foi desenvolvido o conceito de Desenho Universal para a Aprendizagem (DUA), uma derivação do Desenho Universal (RICARDO; SAÇO; FERREIRA, 2017; BOCK; GESSER; NUERNBERG, 2018). O DUA compreende um 
http://dx.doi.org/10.5902/1984686X66118

conjunto de princípios para o desenvolvimento de currículos, com estratégias e ações que visam tornar o ensino acessível e funcional a todas as pessoas, reduzindo barreiras à aprendizagem com um modelo de intervenção que forneça igualdade de oportunidades para aprender (NUNES; MADUREIRA, 2015). Em um ambiente escolar acessível, onde a ampliação de saberes depende, em grande medida, da comunicação verbal entre professor e estudante, é necessário promover meios de fazer essa comunicação ser entendida por todos os alunos. Nesse contexto, o DUA dialoga com a LDB, e abre oportunidades para ampliar a cultura de inclusão no ambiente educacional (BRASIL, 1996).

Os princípios orientadores do DUA destacam a importância de se projetar um ensino pensando na diversidade dos processos de aprendizagem, a fim de não se incorrer no risco de um ensino excludente, no qual o aluno com deficiência não se desenvolve em suas potencialidades. Em vez de se pensar em adaptações específicas para um aluno em particular, em determinada atividade, pensa-se em formas diversificadas de ensinar para todos os estudantes, partindo da ideia de que modos variados de apresentação de um novo conhecimento aumentam as possibilidades de aprendê-lo (ZERBATO; MENDES, 2018). DUA é uma maneira de se pensar a educação que tem o potencial de tornar as experiências de aprendizagem mais acessíveis e significativas. Nesse sentido, a abordagem do DUA procura contornar barreiras à aprendizagem e estimular o desenvolvimento de todos os estudantes (NUNES; MADUREIRA, 2015).

Lev Vigotski, já no início do século, se posicionava contrariamente ao confinamento das crianças com deficiência em instituições separadas do restante da sociedade, uma vez que esses ambientes, ao terem como foco o impedimento biológico, não contribuíam para o olhar sobre as potencialidades dessas crianças. Segundo ele, ao se concentrar nas limitações, deixava-se de lado aquilo que verdadeiramente poderia fazer a diferença no desenvolvimento das pessoas com deficiência: a cultura e a inserção no meio social. $O$ autor soviético defendia, assim, que a escola regular deveria estar apta a dar conta da diversidade humana, promovendo suas potencialidades (VIGOTSKI, 2019).

No texto A defectologia e o estudo do desenvolvimento e da educação da criança anormal (2011), Vigotski afirma que as leis que regem o desenvolvimento das crianças normais (terminologia da época) e das crianças com deficiência, são as mesmas. Em linhas gerais, tais leis se referem ao papel da cultura e da sociedade no desenvolvimento das funções psíquicas superiores. Entretanto, algo particular se passa no desenvolvimento da criança com deficiência: em razão de uma singularidade biológica, alguns caminhos do 
http://dx.doi.org/10.5902/1984686X66118

desenvolvimento estão fechados para ela e, por isso, ela precisa buscar vias indiretas, que são construídas no âmbito da cultura. Essas rotas alternativas enriquecem as práticas humanas e sociais, deixando de estar restritas às pessoas com deficiência e ampliando as potencialidades de desenvolvimento humano como um todo, o que vai ao encontro dos princípios do DUA.

Reconhecer a necessidade de se criarem oportunidades para que todos sejam incluídos, implica o estabelecimento de práticas que permitam múltiplos meios de envolvimento, de representação e de expressão, que possam ampliar as formas de acesso à escola e aos recursos que os alunos necessitam para aprender, por meio de abordagens flexíveis e adequadas às necessidades individuais. Planejar estratégias de ensino considerando o DUA, sugere que o mesmo conteúdo possa ser disponibilizado em diferentes formatos e mídias, dependendo do objetivo a ser trabalhado. Por exemplo, materiais concretos, voltados para a aprendizagem de conteúdos matemáticos por estudantes cegos, podem ter o seu uso ampliado para os demais alunos, beneficiando também a compreensão desses (ZERBATO; MENDES, 2018). Um conceito pode ser apresentado por meio de recursos multimídia como animações, filmes, músicas, fotografias, cartazes ou mapas, de forma que todos os estudantes possam acessá-lo (NUNES; MADUREIRA, 2015).

Observa-se, assim, que, a fim de promover a inclusão dos alunos com deficiência nas práticas educacionais, e o seu acesso aos materiais utilizados em sala de aula, é necessário a utilização de recursos e metodologias que contornem barreiras comunicacionais. No contexto da sala de aula inclusiva, esse recurso de acessibilidade é chamado de Tecnologia Assistiva (TA), e representa uma área do conhecimento que engloba recursos e serviços que auxiliam na ampliação das habilidades funcionais de pessoas com deficiência ou mobilidade reduzida (BRASIL, 2015).

O conceito de TA está centrado no usuário com deficiência e não na própria tecnologia: se, por exemplo, uma pessoa sem deficiência visual escuta um audiolivro enquanto corre na esteira da academia, nesse caso o audiolivro não é uma TA. Entretanto, se o mesmo audiolivro for utilizado por uma pessoa cega, como alternativa ao conteúdo impresso, então será para ela uma TA (VERGARA-NUNES, MACHADO; VANZIN, 2011).

A audiodescrição (AD) pode ser considerada tanto um recurso de TA, que possibilita o acesso ao mundo imagético para as pessoas cegas, como uma ferramenta pedagógica do DUA, pois amplia as opções de acesso ao conhecimento para todos, construções essas 
http://dx.doi.org/10.5902/1984686X66118

que se dão no âmbito da cultura. Acrescentar a $A D$ nessa nova e flexível maneira de ensinar, incrementando a aula com mais descrições explicativas sobre as características visuais de gestos e expressões corporais, bem como dos materiais pedagógicos utilizados no cotidiano da sala de aula, cria alternativas de acesso à comunicação visual para os alunos cegos e promove o desenvolvimento de todos, conforme aprofundaremos no tópico a seguir.

\section{A inclusão escolar de alunos com deficiência visual e a Audiodescrição}

A deficiência visual é caracterizada como a perda total ou parcial da visão, congênita ou adquirida, e pode ser classificada como cegueira ou baixa visão. A cegueira é a perda total da função visual ou pouquíssima capacidade de enxergar. A baixa visão é a perda parcial da função visual, em que "o aluno possui resíduo visual e apresenta capacidade potencial de utilização da visão prejudicada para atividades escolares e de locomoção" (INEP, 2019, p. 7).

Entre os fatores que mais interferem no processo de escolarização do aluno com deficiência visual, estão a falta de recursos, falta de preparo do professor e falta de conhecimento sobre a capacidade de aprendizagem desses alunos. Em muitos casos, a fala do professor constitui praticamente o único recurso para a aprendizagem em sala de aula (NUNES; LOMÔNACO, 2010). A partir dos pressupostos que adotamos nesse estudo, que enfatizam as potencialidades do desenvolvimento humano a partir de recursos socialmente construídos, a cegueira, como singularidade biológica, não pode ser argumento para que um aluno tenha menos oportunidades de aprendizagem do que os alunos sem deficiência. Dessa forma, utilizar a AD didática no contexto da sala de aula, é oferecer ao estudante cego um conhecimento equivalente àquele oferecido ao aluno que enxerga (VERGARA-NUNES, 2016).

$A \mathrm{AD}$ é um recurso de acessibilidade comunicacional que transforma em verbal o visual, e amplia a compreensão de pessoas com deficiência visual em eventos culturais, esportivos, turísticos, acadêmicos e outros, por meio de informação sonora. Na TV, no cinema e no teatro, a $A D$ permite conhecer cenários, características físicas das personagens, expressões faciais, entrada e saída de cena e o desenrolar de ações, que são fundamentais para a construção do entendimento e interpretação de quem assiste. $\mathrm{Na}$ escola, o uso da AD permite que oportunidades sejam equiparadas, eliminando barreiras comunicacionais e possibilitando o acesso ao mundo das imagens. Esse recurso amplia as 
http://dx.doi.org/10.5902/1984686X66118

possibilidades de acesso à cultura e à informação, contribuindo para a inclusão cultural, social e escolar (MOTTA, 2016).

Sendo relativamente nova no Brasil, a AD ainda é desconhecida pela grande maioria dos educadores, mesmo entre aqueles que trabalham com alunos com deficiência visual. Sua utilização ainda está centrada nas grandes cidades. É por meio da AD da TV aberta que muitas pessoas tomam conhecimento da existência do recurso, e acreditam que tem sido aplicado apenas a espaços como cinema, TV e teatro. Dessa forma, aqueles que vivem em pequenos municípios continuam desassistidos e sem acesso ao recurso (MIANES, 2017).

Por outro lado, ainda que nessas pequenas cidades ou municípios não haja um cinema ou teatro, certamente há escolas, e essas são espaços importantes e potencialmente eficazes para a divulgação da $A D$, que pode ser utilizada de diversas formas e em situações diferentes na rotina escolar, desde a descrição de imagens dos livros didáticos, um gráfico desenhado no quadro, uma feira de ciências, um evento cultural ou um filme exibido em sala de aula (MICHELS; SILVA, 2016).

Em razão de sua eficácia no desafio de traduzir em palavras aquilo que os olhos não podem enxergar, mas que os ouvidos podem entender, a AD tem conquistado instituições educacionais. Nelas, as imagens são utilizadas tanto para ilustrar e tornar as aulas mais atraentes, como para complementar o entendimento de um tema estudado ou facilitar sua compreensão. Todas as imagens têm significado, e por isso a importância e necessidade de traduzi-las em palavras, principalmente se considerarmos a diversidade de alunos em sala de aula e as possíveis barreiras comunicacionais que possam existir nesse ambiente (MOTTA, 2016).

Assim, uma vez que materiais multimídia fazem parte da rotina pedagógica, esses recursos também devem estar disponíveis àqueles que não enxergam, e a $A D$ se mostra como uma alternativa privilegiada para isso. Por possuir um caráter inclusivo, a $A D$ possibilita a compreensão de imagens estáticas e dinâmicas simultaneamente por alunos videntes e cegos, ou com baixa visão, equiparando possibilidades de acesso ao universo imagético e às informações nele contidas (SOUSA, 2017).

A AD, por não necessitar de equipamentos para ser realizada, pode ser feita pelo próprio professor por meio da verbalização, sempre que necessário, de tudo aquilo que for visual. $O$ docente pode descrever as imagens contidas nas ilustrações de livros didáticos e livros de história, vídeos, fotografias, experimentos científicos, visitas culturais, dentre outros. Como atores centrais desse espaço de construção de saberes, os docentes 
precisam estar capacitados para fazer a leitura do mundo imagético, bem como para orientar seus alunos a fazê-la (MOTTA, 2016).

Introduzir novas ferramentas que promovam o acesso à realidade das imagens, pode aguçar a curiosidade e ampliar a visão de mundo de todos os alunos, tanto daqueles com deficiência visual como dos demais. Estudos vêm demonstrando que a utilização da $A D$ como ferramenta pedagógica, amplia as oportunidades de aprendizagem não só para os alunos com deficiência visual (cegos e com baixa visão), como também para alunos com dificuldades de aprendizagem, déficit de atenção, dislexia, deficiência intelectual, síndrome de Down, autismo e mesmo alunos sem deficiência (AZEVEDO et al, 2019; MOTTA, 2016; PAVÃO; PAVÃO, 2010). Essa abordagem, inclusive, representa um grande diferencial no aprendizado de alunos surdos, que, com o auxílio do intérprete de Libras, recebe mais informações sobre as imagens e a rede de significados a elas atribuídos, possibilitando um entendimento mais amplo do mundo (RIBEIRO; LIMA, 2012).

A AD, em ambientes educacionais, não precisa estar presa aos parâmetros utilizados para TV, cinema ou teatro, ao contrário, é importante que ela se volte para as especificidades dos processos pedagógicos, ao trazer informações que possibilitem aos alunos com deficiência visual construir conhecimento por meio das imagens (VERGARANUNES, 2016). A AD com fins didáticos pode ser mais informativa do que apenas tradutória, pois o professor pode (e deve) inserir elementos que não constem diretamente na imagem, mas que permitam aos alunos construírem o seu sentido (MIANES, 2017).

A AD, como instrumento de mediação, possibilita uma melhor participação dos alunos cegos nas atividades escolares. Uma vez que as mensagens contidas nas imagens foram transmitidas ao mesmo tempo para todos, possibilita-se que alunos cegos tenham maior confiança e autonomia nas discussões em grupo, sendo capazes de tecer inferências, deduções e conclusões (MOTTA, 2016).

Além de realizar a AD de imagens dinâmicas e estáticas utilizadas em sala de aula, é importante, igualmente, que o professor descreva gestos, atos e comportamentos; por exemplo, avisar quando for escrever no quadro ou pegar determinado material. Procedimentos como esses facilitam a aprendizagem do aluno cego. Esse processo de buscar palavras diversas para descrever elementos visuais e imagéticos utilizados em sala de aula, aumenta a fluência verbal de todos, e tem o potencial de tornar as experiências mais significativas, independentemente se os estudantes tenham ou não deficiência visual (MOTTA, 2016). 
http://dx.doi.org/10.5902/1984686X66118

\section{A Audiodescrição na Educação Infantil como ferramenta do Desenho Universal para a Aprendizagem}

A Educação Infantil, início da educação formal, é a etapa na qual se estabelecem fundamentos necessários ao desenvolvimento global da criança. O ingresso na pré-escola ou creche é, frequentemente, a primeira separação dessa do espaço e dos vínculos familiares; por isso, a escola deve articular suas propostas pedagógicas às experiências e conhecimentos trazidos pelas crianças, a fim de se ampliarem vivências, conhecimentos e habilidades. De acordo com a Base Nacional Comum Curricular (BNCC), o foco da Educação Infantil deverá ser dado, especialmente, na socialização, na comunicação e na autonomia. Nessa etapa, o contato com a diversidade humana e o acesso a formas variadas de comunicação, podem favorecer as relações sociais (BRASIL, 2018).

A BNCC sublinha o caráter fundamental da Educação Infantil na construção identitária e subjetiva da criança. Além de estabelecer direitos de aprendizagem para crianças de 0 a 5 anos, o documento deixa claro que, para efetivar esses direitos, é preciso haver um trabalho com intencionalidade, a fim de se garantir que as estratégias pedagógicas estejam alinhadas aos fatores considerados fundamentais no processo (BRASIL, 2018). Nesse contexto, pensar em abordagens baseadas nos princípios do DUA abre alternativas de acesso ao conhecimento, podendo ampliar oportunidades de aprendizagem para toda a turma.

De acordo com a teoria histórico-cultural de Lev Vigotski, o desenvolvimento da criança deve ser compreendido de modo contextualizado, uma vez que ocorre por meio do entrelace mútuo, e constante, de fatores biológicos e sociais. Coloca-se, dessa forma, a atividade social como determinante para o desenvolvimento psíquico humano. Nessa perspectiva, defende-se que a aprendizagem conduz ao desenvolvimento, logo, é dever da escola sistematizar o conhecimento elaborado, e socializá-lo de forma engajada com a formação integral da criança (VIGOTSKI, 2019).

Para que a construção de um ambiente favorável ao desenvolvimento da criança com deficiência visual não seja comprometida, é indispensável o estabelecimento de estratégias criativas, e uma abertura sobre o que é possível alcançar com as crianças. Essas estratégias devem acolher suas diferenças e focar os estímulos em suas potencialidades, pois o processo de interação da criança com o meio e com as dificuldades que enfrenta, 
http://dx.doi.org/10.5902/1984686X66118

em razão da deficiência, impulsionam o seu avanço por meio de compensações criativas e culturalmente embasadas (VIGOTSKI, 2011).

A criança cega necessita de experiências táteis, cinestésicas e auditivas no mundo em que vive. Muito do que se estabelece nas relações sociais é de ordem não verbal, pois as pessoas falam com os olhos e com o corpo. Essa comunicação não verbal não acontece de forma espontânea, já que são expressões aprendidas por meio da imitação do outro. Existem muitos sentimentos e expressões identificáveis apenas visualmente, e a criança cega também vivencia esses sentimentos, mas, para externá-los facialmente, é preciso que seja estimulada. O sorriso, por exemplo, é aprendido. Por isso, é importante incentivar a estimulação da criança ainda bebê, com a criação de situações prazerosas, que estimulem sensações diferentes. Dessa forma, as interações sociais devem ser ricas em estímulos variados para que a aprendizagem possa impulsionar o desenvolvimento. As crianças cegas, como todas as crianças, também se apropriam das situações lúdicas, para compor hipóteses, formular e rever conceitos sobre o mundo e ressignificar o ambiente (GALVÃO, 2012).

Uma vez que o sentido da visão não está disponível, todo o organismo se reorganiza para que as funções restantes trabalhem juntas de modo a encontrar rotas alternativas àquelas obstruídas pela deficiência, processando estímulos externos e utilizando-se de outros recursos para compensar o sentido ausente. Em vez de focar no impedimento, cabe à escola estimular as potencialidades da criança e motivá-la a contornar suas dificuldades, aplicando métodos e procedimentos que as permitam acessar o conhecimento, transformando-o em aprendizado. Esse processo de desenvolvimento depende da realidade social e da qualidade dos estímulos que recebe, pois é do processo de interação da criança com o meio que nasce a situação que a impele a avançar pelo caminho da compensação, que é, em grande medida, a vida social e coletiva da criança (VIGOTSKI, 2019).

Para além das especificidades da criança com deficiência visual, Vigotski (2000) afirma que é no coletivo que todas as crianças desenvolvem as funções superiores, como a consciência de si e o uso social da linguagem, e que o primeiro estágio da fala infantil é a descoberta da função simbólica da linguagem. O desenvolvimento da fala associa-se também ao desenvolvimento do pensamento, em um processo dialético de internalização e exteriorização, em que novas palavras trazem consigo novos significados, 
http://dx.doi.org/10.5902/1984686X66118

complexificando os processos cognitivos, bem como as possibilidades de ação sobre o mundo.

Tendo em vista que o desenvolvimento e a aprendizagem infantil ocorrem em um contexto social e cultural mediados pela linguagem e, por isso, não se restringem à captação de informações sensoriais, são necessárias situações que promovam associações e internalização de significados socialmente construídos e compartilhados (MOTTA, 2016). Em consonância com esses postulados, a BNCC afirma que:

Na Educação Infantil, é importante promover experiências nas quais as crianças possam falar e ouvir, potencializando sua participação na cultura oral, pois é na escuta de histórias, na participação em conversas, nas descrições, nas narrativas elaboradas individualmente ou em grupo e nas implicações com as múltiplas linguagens que a criança se constitui ativamente como sujeito singular e pertencente a um grupo social (BRASIL, 2018).

Nesse contexto, a contação de histórias é bastante utilizada como recurso pedagógico, tendo em vista que esse momento de experiência estética e fruição artística resgata memórias, promove a imaginação e amplia a visão de mundo, fatores essenciais ao letramento (MOTTA, 2016). Promover contações de histórias e incorporar a AD para caracterizar personagens, cenários e cores, proporciona, por meio da troca de experiências, a ampliação do conhecimento de mundo, permitindo que a criança se torne a protagonista do seu próprio desenvolvimento (SILVA; FEITOSA; MOTA, 2019).

Traduzir em palavras as imagens dos livros, auxilia na construção de imagens mentais e possibilita aos alunos com deficiência visual conhecer todos os elementos que as ilustrações trazem, e que são impregnadas de significados que complementam o próprio texto. Chamar a atenção para os recursos imagéticos, utilizando uma variedade de elementos descritivos durante a contação, é um diferencial para que todos participem da atividade, se encantem pelo colorido das páginas dos livros e pelas feições e vestimentas das personagens. As cores possuem significados e nos remetem a sentimentos e emoções socialmente construídos. A busca por mais e mais palavras para descrever cenários, cores e texturas, contribui consideravelmente para a expansão do vocabulário de toda a turma, independentemente se tenham ou não deficiência visual (MOTTA, 2016).

Para que a vivência seja significativa, as práticas do professor devem estar diretamente comprometidas com as necessidades e interesses da criança. Isso implica a elaboração de maneiras de incluí-la em situações de brincadeiras que explorem o espaço, o corpo e diferentes movimentos, bem como noções de quantidade, cores e formas 
http://dx.doi.org/10.5902/1984686X66118

(BRASIL, 2018). Elaborar atividades com estratégias concebidas de acordo com o DUA, que prevê alternativas variadas e flexíveis na apresentação por parte do professor, além de possibilitar a participação das crianças cegas nas atividades, pode ampliar as possibilidades de aprendizagem significativa - e, logo, de desenvolvimento - para toda a turma (NUNES; MADUREIRA, 2015).

Por meio da $A D$, as crianças cegas podem adquirir conhecimentos sobre o mundo visual e sobre as normas de interações sociais, como vestuário e linguagem corporal. É nesse sentido que Motta (2016) insere a AD como um instrumento de mediação, que pode auxiliar os alunos a fazerem inferências, deduções e chegarem a conclusões. A AD facilita o entendimento e fortalece laços com o grupo, além de contribuir para o desenvolvimento da linguagem de toda a turma. Daí a importância de uma educação que Ihes permita explorar o mundo e o seu próprio potencial. Reitera-se, assim, que conhecer a AD e utilizála como uma ferramenta do DUA, pode enriquecer as práticas pedagógicas e proporcionar maiores oportunidades de aprendizagem e desenvolvimento na Educação Infantil, tanto para crianças com deficiência visual, como para as que tenham deficiência intelectual, dislexia, déficit de atenção, autistas e, inclusive, crianças sem deficiência.

\section{Considerações finais}

A partir do objetivo e do debate estabelecidos nesse texto, entende-se que a $A D$, como recurso de Tecnologia Assistiva, se apresenta como uma fonte inesgotável de acessibilidade de baixo custo. Se utilizada também como uma ferramenta do Desenho Universal para a Aprendizagem, que visa criar situações de aprendizagem para o maior número possível de alunos, pode abrir novas oportunidades de ensino e aprendizagem benéficas a todos os envolvidos nesse contexto.

Ao detalhar aspectos dos objetos e esclarecer informações contidas nas imagens utilizadas no dia a dia da sala de aula da Educação Infantil, o professor pode favorecer a aprendizagem e contornar barreiras comunicacionais, ampliando as possibilidades para a apreensão do mundo, seus códigos, sentidos e significados. Descrever tanto os materiais pedagógicos, como o ambiente escolar como um todo, proporciona um maior senso de pertencimento das crianças cegas e pode potencializar, ainda, o aprendizado de outros. Nesse contexto, a $A D$ representa uma ponte robusta que pode conduzir a criança com deficiência visual a uma aprendizagem muito mais significativa. Além dos seus visíveis 
benefícios aos que não enxergam, pode ser proveitosa também, tanto para alunos com deficiência intelectual, quanto para aqueles sem deficiência.

De acordo com a perspectiva histórico-cultural, um contexto de ensinoaprendizagem bem planejado pelo professor em sala de aula, além de ser determinante para o comportamento da turma com o colega com deficiência, se configura como fator essencial ao seu desenvolvimento. A mudança na postura do professor ao incluir mais explicações descritivas e detalhadas em sua aula, possibilita maior participação das crianças com deficiência visual nos conteúdos e tarefas escolares, e oferece maior confiança aos alunos cegos nas atividades em grupo, de forma que se sentirão mais seguros para expor suas ideias, tanto quanto seus colegas que enxergam. Essa mediação adequada, fortalece a experiência, tornando a compreensão muito mais profunda, e possibilitando a incorporação de novos conhecimentos e o estabelecimento de uma rede de significados mais ampla.

As metodologias, gestos, livros, vídeos, filmes, imagens e os demais elementos visuais presentes no cotidiano da Educação Infantil, podem ser acessíveis às crianças com deficiência visual. Utilizar a $A D$ como uma ferramenta pedagógica, permitirá que essas entendam as mensagens transmitidas visualmente e, assim, participem da cultura visual do ambiente em que estão inseridas. Quanto mais produtos e materiais audiodescritos a criança conhecer, maiores as possibilidades de promover aprendizagens significativas que ampliarão sua percepção de mundo, proporcionando maior qualidade de vida e inclusão social.

É de fundamental importância que toda a comunidade acadêmica tenha uma visão mais humana e acessível do mundo em que vivem, para que todos possam, juntos, construir espaços educativos de convivência mais justos, inclusivos e acolhedores. Entende-se, com esse estudo, que o uso da audiodescrição como ferramenta pedagógica do Desenho Universal para a Aprendizagem, abre muitas possibilidades tanto para professores, como para discentes na Educação Infantil. Estudos mais aprofundados e pesquisas empíricas sobre o seu uso em todas as etapas da educação básica, devem ser realizados a fim de contribuir com a ampliação do conhecimento de professores e comunidade acadêmica, de modo que as pessoas com deficiência visual tenham melhores oportunidades de exercer seu direito à aprendizagem. 
http://dx.doi.org/10.5902/1984686X66118

\section{Referências}

AZEVEDO, Tássia Lopes de. et al. Uso da audiodescrição no brincar de uma criança com síndrome de Down na educação infantil. Revista Educação Especial. Santa Maria, v. 32 , 2019. Disponível em: https://periodicos.ufsm.br/educacaoespecial/article/view/23667/html. Acesso em: 9 mai. 2021.

BOCK, Geisa Letícia Kempfer; GESSER, Marivete; NUERNBERG, Adriano Henrique. Desenho Universal para a Aprendizagem: a Produção Científica no Período de 2011 a 2016. Revista brasileira de educação especial. Bauru, v. 24, n. 1, mar. 2018. Disponível em: http://www.scielo.br/scielo.php?script=sci_arttext\&pid=S141365382018000100143\&lng=en\&nrm=iso. Acesso em: 11 mai. 2021.

BRAGA, Klístenes Bastos; ARAÚJO, Vera Lúcia Santiago. A audiodescrição aplicada à tradução de videoaulas utilizadas na modalidade de educação a distância no ensino superior. In: VILLELA, Lucinéa Marcelino; MARTINS, Sandra Eli Sartoreto de Oliveira; LEITE, Lúcia Pereira (Orgs.). Recursos de Acessibilidade aplicados ao Ensino Superior. Bauru, SP: FC/Unesp, 2015. p. 11-20.

BRASIL. Ministério da Educação. Lei de Diretrizes e Bases da Educação Nacional. Brasília, DF, 1996. Disponível em:

http://portal.mec.gov.br/seesp/arquivos/pdf/lei9394_ldbn2.pdf. Acesso em: 3 ago. 2020.

BRASIL. Ministério da Educação. Plano Nacional de Educação. Brasília, DF, 2001. Disponível em: http://www.planalto.gov.br/ccivil_03/leis/leis_2001/l10172.htm. Acesso em: 20 mai. 2021.

BRASIL. Ministério da Educação. Política Nacional de Educação Especial na Perspectiva da Educação Inclusiva. Brasília, DF, 2008. Disponível em:

http://portal.mec.gov.br/arquivos/pdf/politicaeducespecial.pdf. Acesso em: 5 jun. 2021.

BRASIL. Ministério das Relações Exteriores. Convenção Internacional sobre os

Direitos das Pessoas com Deficiência. Brasília, DF, 2009. Disponível em:

http://www.planalto.gov.br/ccivil_03/_ato2007-2010/2009/decreto/d6949.htm. Acesso em: 15 mai. 2021.

BRASIL. Ministério da Educação. Plano Nacional de Educação. Brasília, DF, 2014. Disponível em: http://pne.mec.gov.br/18-planos-subnacionais-de-educacao/543-planonacional-de-educacao-lei-n-13-005-2014. Acesso em: 10 fev. 2021.

BRASIL. Lei Brasileira de Inclusão da Pessoa com Deficiência. Brasília, DF, 2015. Disponível em:

https://www.cnmp.mp.br/portal/images/lei_brasileira_inclusao_pessoa_deficiencia.pdf. Acesso em: 10 ago. 2020.

BRASIL. Ministério da Educação. Base Nacional Comum Curricular. Brasília: DF, 2018. Disponível em:

http://basenacionalcomum.mec.gov.br/images/BNCC_El_EF_110518_versaofinal_site.pdf . Acesso em: 6 fev. 2021. 
http://dx.doi.org/10.5902/1984686X66118

BRUNO, Maria Moraes Garcia. Educação Infantil: saberes e práticas da inclusão. Brasília: MEC, Secretaria de Educação Especial, 2006. Disponível em:

http://portal.mec.gov.br/seesp/arquivos/pdf/introducao.pdf. Acesso em: 17 fev. 2021.

COZENDEY, Sabrina Gomes; COSTA, Maria da Piedade Resende. Utilizando a audiodescrição como um recurso de ensino. Revista Ibero-Americana de Estudos em Educação, Araraquara, v. 13, n. 03, jul./set., 2018. Disponível em: https://dialnet.unirioja.es/servlet/articulo?codigo=6683640. Acesso em: 9 mai. 2021.

GALVÃO, Nelma de Cassia Silva Sandes. Construindo um ambiente de aprendizagem e desenvolvimento para e com a criança cega. In: ARAPIRACA, Mary de Andrade; BELTRÃO, Licia Maria freire; SILVA, Cleverson Suzart. (Org.). Estudos e passagens do Proinfantil na Bahia. Salvador: EDUFBA, 2012. p. 101-122.

IBGE. Instituto Brasileiro de Geografia e Estatística. Censo demográfico 2010.

Características gerais da população, religião e pessoas com deficiência. Rio de Janeiro: IBGE, 2010. Disponível em:

http://biblioteca.ibge.gov.br/visualizacao/periodicos/94/cd_2010_religiao_deficiencia.pdf. Acesso em: 19 mai. 2017

INEP. Instituto Nacional de Estudos e Pesquisas Educacionais Anísio Teixeira. Glossário da Educação Especial. Censo Escolar 2019. Brasília, DF: INEP/MEC, 2019. Disponível em:

https://download.inep.gov.br/educacao_basica/educacenso/situacao_aluno/documentos/20 19/glossario_da_educacao_especial_censo_escolar_2019.pdf. Acesso em: 20 mai. 2021.

MANTOAN, Maria Teresa Eglér. Inclusão escolar. O que é? Por quê? Como fazer? São Paulo: Summus, 2015.

MIANES, Felipe Leão. A Audiodescrição vai à Sala de Aula: do desconhecimento a uma formação docente inclusiva. In: Seminário brasileiro de estudos culturais e educação, 7. 2017, Canoas-RS. Anais do 7º Seminário Brasileiro de Estudos Culturais e Educação, Canoas-RS: PPGEDU, 2017. Disponível em:

http://www.2017.sbece.com.br/resources/anais/7/1495132445_ARQUIVO_AAUDIODESCRI CAOVAIASALADEAULA.pdf. Acesso em: 6 ago. 2020.

MICHELS, Lísia Regina Ferreira; SILVA, Mara Cristina Fortuna. A audiodescrição na escola. In: CARPES, Daiana Stockey. Audiodescrição: práticas e reflexões. Santa Cruz do Sul, RS: Editora Catarse, 2016.

MOTTA, Lívia Maria Villela de Mello. Audiodescrição na escola: abrindo caminhos para a leitura de mundo. Campinas: Editora Pontes, 2016.

NUNES, Sylvia.; LOMÔNACO, José Fernando Bitencourt. O Aluno Cego: Preconceitos e Potencialidades. Revista Brasileira de Psicologia Escolar e Educacional, São Paulo, v. 14, n. 1, jan./jun. 2010. Disponível em: https://www.scielo.br/pdf/pee/v14n1/v14n1a06. Acesso em: 6 fev. 2021.

NUNES, Maria; MADUREIRA, Isabel. Desenho universal para a aprendizagem: construindo práticas pedagógicas inclusivas. Da Investigação às Práticas. Lisboa, v. 5, n. 2, jul. 2015. Disponível em: http://hdl.handle.net/10400.21/5211. Acesso em: 9 mai. 2021. 
PASSERINO, Liliana Maria; CRUZ, Ana Maria Lima. Mídias na educação inclusiva: um estudo do uso da audiodescrição no ensino médio. In: TAROUCO, Liane Margarida Rockenbach; ABREU, Cristiane de Souza (Orgs.). Mídias na educação: a pedagogia e a tecnologia subjacentes. Porto Alegre: Evangraf, 2017, v. 1, p. 49-65. Disponível em: https://www.lume.ufrgs.br/bitstream/handle/10183/169656/001051855.pdf?sequence=1. Acesso em: 9 mai. 2021.

PAVÃO, Ana Cláudia Oliveira; PAVÃO, Sílvia Maria de Oliveira. Audiodescrição na intervenção pedagógica das dificuldades de aprendizagem. Educação e Fronteiras, Dourados, v. 10, n. 28, nov. 2020. Disponível em:

https://ojs.ufgd.edu.br/index.php/educacao/article/view/13014/6336. Acesso em: 10 mai. 2021.

PLETSCH, Márcia Denise; SOUZA, Flávia Faissal; ORLEANS, Luis Fernando. A diferenciação curricular e o desenho universal na aprendizagem como princípios para a inclusão escolar. Revista Educação e Cultura. Rio de Janeiro, v. 14, n. 36, 2017. Disponível em: http://periodicos.estacio.br/index.php/reeduc/article/view/3114/1662. Acesso em: 9 mai. 2021.

RIBEIRO, Ernani Nunes; LIMA, Francisco José. Contribuições da áudio-descrição para a aprendizagem de educandos surdos. Revista Brasileira de Tradução Visual - RBTV, v. 2, 2012. Disponível em: https://www.researchgate.net/profile/Francisco-Lima10/publication/267555553_Contribuicoes_da_audiodescricao_para_a_aprendizagem_de_educandos_surdos/links/560bf53108ae73e7a6a2d0 9a/Contribuicoes-da-audio-descricao-para-a-aprendizagem-de-educandos-surdos.pdf. Acesso em: 9 mai. 2021.

RICARDO, Débora Cristina; SAÇO, Lívia Fabiana; FERREIRA, Eliana Lúcia. O desenho universal na educação: novos olhares diante da inclusão do ser deficiente. Revista lberoAmericana de Estudos em Educação, Araraquara, v. 12, n. esp. 2, 2017. Disponível em: https://periodicos.fclar.unesp.br/iberoamericana/article/view/10083. Acesso em: 11 mai. 2021

RIOS, Gabriela Alias. et al. Audiodescrição e inclusão na educação a distância: experiência do núcleo de educação a distância da UNESP. Journal of Research in Special Educational Needs. Lisboa, v. 16, n. s1, 2016. Disponível em: https://nasenjournals.onlinelibrary.wiley.com/doi/epdf/10.1111/1471-3802.12145 Acesso em: 9 mai. 2021

SASSAKI, Romeu Kazumi. Inclusão: acessibilidade no lazer, trabalho e educação. Revista Nacional de Reabilitação (Reação), São Paulo, ano XII, mar./abr. 2009. Disponível em: https://files.cercomp.ufg.br/weby/up/211/o/SASSAKI__Acessibilidade.pdf?1473203319. Acesso em: 6 ago. 2020.

SILVA, Alexandra Moura. Leitura de Imagens na sala de aula: arte, cultura visual e intertextualidade. Revista Matéria Prima, v. 3, n. 2, 2015. Disponível em: https://repositorio.ul.pt/bitstream/10451/27888/2/ULFBA_Materiaprima_V3N2_p229240.pdf. Acesso em: 6 ago. 2020. 
http://dx.doi.org/10.5902/1984686X66118

SILVA, Maria de Loudes; FEITOSA, Francisca Silva; MOTA, Janine. Contação de História: Benefícios e contribuições na Educação Infantil. 2019. Disponível em: https://revista.unitins.br/index.php/humanidadeseinovacao/article/view/1869 . Acesso em: 6 fev. 2021.

SOUSA, Ivan Vale de. Audiodescrição: o que é? Como se faz?. Revista Edapeci, São Cristóvão, v. 17, n. 13, set./dez. 2017. Disponível em:

https://dialnet.unirioja.es/servlet/articulo?codigo=6711168. Acesso em: 7 mai. 2021.

VERGARA-NUNES, Elton; MACHADO, Flávia Oliveira; VANZIN, Tarcísio. Audiodescrição como tecnologia assistiva para acesso ao conhecimento por pessoas cegas. In:

ULBRICHT, Vania Ribas; VANZIN, Tarcísio; VILLAROUCO, Vilma. (Org.). Ambiente virtual de aprendizagem inclusivo. Florianópolis: Pandion, 2011. p. 189-232.

VERGARA-NUNES, Elton. Audiodescrição Didática. Tese (Doutorado em Engenharia e Gestão do Conhecimento). Pelotas: Universidade Federal de Pelotas, 2016. Disponível em:

https://repositorio.ufsc.br/xmlui/bitstream/handle/123456789/167796/341239.pdf?sequenc e=1\&isAllowed=y. Acesso em: 6 ago. 2020.

VIGOTSKI, Lev Semionovitch. A Construção do Pensamento e da Linguagem. São Paulo: Martins Fontes, 2000.

VIGOTSKI, Lev Semionovitch. A defectologia e o estudo do desenvolvimento e da educação da criança anormal. Educação e Pesquisa, São Paulo, v. 37, n. 4, p. 863-869, dez. 2011.

VIGOTSKI, Lev Semionovitch. Acerca dos processos compensatórios no desenvolvimento da criança mentalmente atrasada. Educação e Pesquisa. São Paulo, v. 44, 2019.

Disponível em: https://www.scielo.br/scielo.php?pid=S1517-

97022018000100750\&script=sci_arttext. Acesso em: 13 fev. 2021.

UNESCO. Declaração Mundial sobre Educação para Todos. Brasília: UNESCO, 1990. Disponível em: https://www.unicef.org/brazil/declaracao-mundial-sobre-educacao-paratodos-conferencia-de-jomtien-1990. Acesso em: 11 mai. 2021

UNESCO. Declaração de Salamanca. Brasília: UNESCO, 1994. Disponível em: http://portal.mec.gov.br/seesp/arquivos/pdf/salamanca.pdf. Acesso em: 6 ago. 2020.

ZERBATO, Ana Paula, MENDES, Enicéia Gonçalves. Desenho Universal para aprendizagem como estratégia de inclusão escolar. Educação Unisinos. São Leopoldo, v. 22, n. 2, 2018. Disponível em:

http://www.revistas.unisinos.br/index.php/educacao/article/view/edu.2018.222.04/6074620 7. Acesso em: 6 fev. 2021. 